\title{
MANAJEMEN KULTUR ROTIFER DENGAN TANGKI VOLUME KECIL
}

\author{
Philip Teguh Imanto \\ Balai Besar Riset Perikanan Budidaya Laut \\ Jl. Br. Gondol, Kec. Gerokgak, Kab. Buleleng, Singaraja-Bali 81101 \\ E-mail:philip_imanto@yahoo.co.id
}

Naskah diterima: 4 Agustus 2008; Diterima publikasi: 20 April 2009

\begin{abstract}
ABSTRAK
Keberhasilan pembenihan ikan sangat dipengaruhi keberhasilan produksi jasad pakan rotifer secara tepat dan efisien. Penelitian kultur rotifer dengan tangki volume kecil bertujuan untuk mendapatkan efisiensi produksi yang paling optimal dan memenuhi prinsip dasar akuakultur low volume high density. Penelitian menggunakan tangki polyethylene dengan volume $500 \mathrm{~L}$ dan volume media awal $100 \mathrm{~L}$, padat tebar awal 200 ind. rotifer per $\mathrm{mL}$ dengan sediaan pakan dasar fitoplankton Nannocloropsis occulata, ragi roti $(0,05 \mathrm{~g} / \mathrm{mio}$.rot./feeding) dan suplemen Scott emulsion $(0,005 \mathrm{~g} /$ mio.rot./feeding). Penelitian dilakukan secara bertahap; tahap pertama (I) tanpa penambahan air laut, peningkatan volume hanya dari penambahan 15 L Nannochloropsis tiap hari sampai hari kelima, tahap kedua (II) dengan penambahan alga $40 \mathrm{~L}$ dan air laut $40 \mathrm{~L}$; serta tahap ketiga (III) dengan menggandakan pemberian ragi roti. Hasil penelitian menunjukkan bahwa pada percobaan tahap I: total produksi rata-rata $122,37 \times 10^{6}$ ind. rotifer, pada tahap II: $97,67 \times 10^{6}$ ind. rotifer, dan pada tahap III: dicapai rata-rata total produksi tertinggi dengan $187,17 \times 10^{6}$ ind. rotifer per tanki kultur 500 L. Pengelolaan kultur pada tahap III memberikan hasil terbaik dengan simpangan terkecil antar tangki kultur ulangan, dan membuktikan sebagai pengelolaan terbaik untuk kultur rotifer dengan tangki volume kecil.
\end{abstract}

KATA KUNCI: rotifer, kultur, volume kecil, efisiensi produksi

\section{ABSTRACT: Management of rotifer culture using small volume tank. By} Philip Teguh Imanto

Success of marine seed production is highly influenced by effective and efficient production performance of life food rotifer. Observation on rotifer culture using small volume tank was aimed to get the optimum production and efficiency, to fulfill the basic principle of aquaculture "low volume high density". Polyethylene tanks of $500 \mathrm{~L}$. were used as culture container, with initial 100 liter sea water as culture medium and initial density of 200 ind. rotifer per $\mathrm{mL}$. N. occulata, baker yeast $(0.05 \mathrm{~g} / \mathrm{mio}$. rotifer/ feeding) and Scott emulsion (0.005 g/mio.rotifer/feeding) were used as basic feed, and applied differently among three trials. First trial without seawater addition, increasing volume of culture media was only from $15 \mathrm{~L}$. of $\mathrm{N}$. occulata within 5 days culture, second trial was done with addition of seawater of $40 \mathrm{~L}$ and $40 \mathrm{~L} \mathrm{of} \mathrm{N}$. occulata every day; and the last trial with twice dosage of baker yeast from trial I and II. The result showed that the average total production from the first trial was $122.37 \times 10^{6}$ ind. rotifer and the second trial was decreased to $97.67 \times 10^{6}$ ind. rotifer. Highest average total production was achieved by the last trial with $187.17 \times 10^{6}$ ind. rotifer per culture tank 500 L. Culture management on the third trial gave the best result with the lowest deviation among replication tanks, and proved as the best management practice for small-scale culture container.

KEYWORDS: rotifer, culture, small volume tanks 


\section{PENDAHULUAN}

Pembenihan ikan laut merupakan mata rantai pertama dari upaya pengembangan budidaya ikan laut, keberhasilan produksi benih ikan laut baik dari segi kuantitas dan kualitas sangat dipengaruhi oleh keberhasilan penyediaan jasad pakan serta manajemen pakan untuk larva ikan laut secara tepat dan efisien.

Rotifer merupakan salah satu jenis zooplankton yang sangat penting pada kegiatan pembenihan ikan laut dan peranannya hingga hari ini belum tergantikan. Menurut Sulkin \& Epifanio dalam Christiansen \& Yang (1976), rotifer mampu memberikan sintasan yang lebih tinggi pada larva kepiting sampai fase zoea III dan secara nyata mempercepat proses moulting ke fase zoea II. Rotifer merupakan pakan alami yang dominan dipilih oleh larva kakap merah (Lutjanus sebae) pada umur 4-8 hari (Melianawati \& Imanto, 2004). Rotifer juga merupakan pakan utama larva Epinephelus sp. dan Plecoglossus altivelis (Liao et al., 1991). Keunggulan rotifer sebagai jasad pakan adalah ukurannya kecil (150-220 $\mu \mathrm{m})$ dan berenang lambat sehingga mudah dimangsa oleh larva (Rusdi, 1997), waktu kultur yang relatif singkat serta mempunyai laju reproduksi yang tinggi (Giliberto \& Mazzola, 1981).

Berbagai penelitian tentang kultur rotifer telah banyak dilakukan seperti penambahan vitamin $B_{12}$ dan pengkayaan fitoplankton (Utyani, 1992; Sumiarsa et al., 1996), dengan pemberian Nannochloropsis occulata awetan yang diperkaya dengan vitamin B- ${ }_{12}$ (Ismi \& Wardoyo, 1997), Pemberian $\alpha$-Tokoferol (vitamin E) (Hendry, 1993), pemberian ragi roti, minyak ikan dan kuning telur (Waspada et al., 1991), pemberian ragi, Chlorella dan Tetraselmis sp. (Rahmasari, 1989). Penelitianpenelitian terdahulu lebih terfokus pada unsur-unsur nutrisi, belum banyak yang menyinggung tentang pengelolaan kultur berdasarkan volume wadah, dimana kestabilan produksi jasad pakan rotifer adalah hal yang mutlak dan harus selalu ada.

Kepastian jumlah produksi merupakan hal terpenting untuk kesuksesan produksi benih ikan laut. Pengelolaan secara terarah perlu dilakukan dengan penerapan produksi pada wadah yang terbatas (sangat terkontrol) tetapi dengan produktivitas cukup tinggi yang bertujuan untuk meningkatkan keberhasilan produksi. Hal yang sering terjadi pada kultur dengan wadah terbatas adalah keterlambatan perkembangan populasi rotifer dan bahkan terjadi kematian (Rusdi, 1997). Oleh karena itu, perlu diupayakan pengelolaan (manajemen) kultur yang tepat dengan wadah terbatas dan jumlah produksi yang tinggi serta stabil, sehingga terpenuhi prinsip dasar akuakultur yaitu low volume high density.

\section{BAHAN DAN METODE}

Penelitian dilakukan di Balai Besar Riset Perikanan Budidaya Laut Gondol-Bali. Rotifer yang digunakan termasuk type-S dengan ratarata panjang lorika $210 \mu \mathrm{m}$ dan lebar $110 \mu \mathrm{m}$ yang dikenal sebagai Brachionus rotundiformis (Suzuki, 1983 dalam Fukusho, 1989), ukuran antara 150-220 um (Rusdi, 1997), atau sekitar 125-300 $\mu \mathrm{m}$ (Fulks \& Main, 1991). Wadah penelitian adalah kontainer Polyethylene (hitam) volume 500 L. dilengkapi dengan sistem aerasi (Gambar 1).

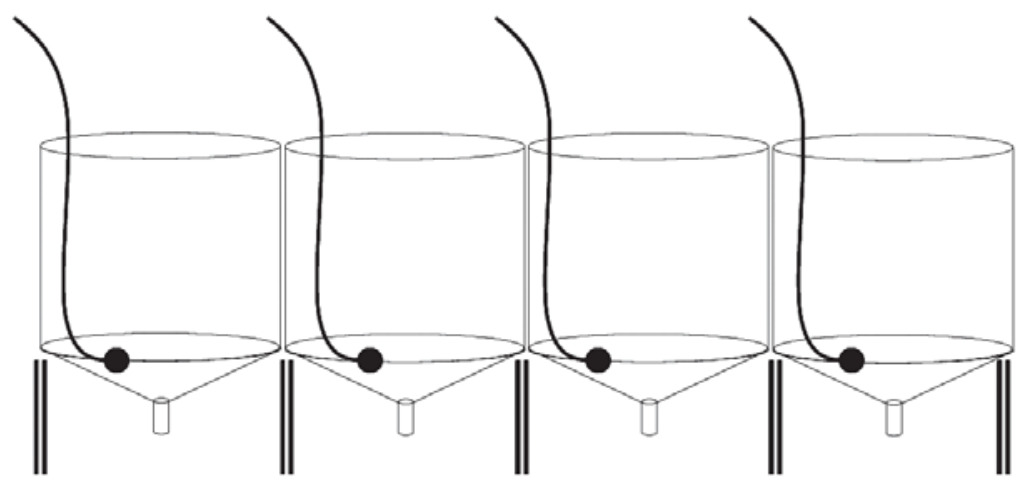

Gambar 1. Tangki kultur rotifer dari bahan polyethylene

Figure 1. Rotifer cultur tank made from polyethylene material 
Tabel 1. Rancangan penelitian dengan tiga tahap pengujian

Table 1. Research planning with three-step trial

\begin{tabular}{lccc}
\hline \multicolumn{1}{c}{ Paramet er } & \multicolumn{3}{c}{ Tahap (Trial) } \\
\cline { 2 - 4 } & $\mathrm{I}$ & $\mathrm{II}$ & $\mathrm{III}$ \\
\hline $\begin{array}{l}\text { Volume awal air } \\
\text { Initial volume of water (L) }\end{array}$ & 100 & 100 & 100 \\
$\begin{array}{l}\text { Minimum kepadatan awal } \\
\text { Minimum initial density (ind.rot./mL) }\end{array}$ & $>200$ & $>200$ & $>200$ \\
$\begin{array}{l}\text { Ragi roti } \\
\text { Beaker yeast (g/mio.rot./feeding) }\end{array}$ & 0.05 & 0.05 & 0.1 \\
$\begin{array}{l}\text { Scott e mulsion } \\
\text { Scott emulsion (g/mio.rot./feeding) }\end{array}$ & 0.005 & 0.005 & 0.005 \\
$\begin{array}{l}\text { Frekuensi pakan } \\
\text { Feeding frequency (time a day) }\end{array}$ & 4 & 4 & 4 \\
$\begin{array}{l}\text { Nannoc hloropsis } \\
\text { Algae (nanno) (L (twice a day) }\end{array}$ & 7.5 & 20 & 20 \\
$\begin{array}{l}\text { Air laut segar } \\
\text { Fresh sea water (L/day) }\end{array}$ & 0 & 40 & 40 \\
$\begin{array}{l}\text { Penghitungan } \\
\text { Counting (AM) }\end{array}$ & $10: 00$ & $10: 00$ & $10: 00$ \\
\hline
\end{tabular}

Pakan yang digunakan pada penelitian ini adalah alga Nannochloropsis oculata dari kultur massal, ragi roti ( $S$. cerevisiae) dan Scott's emulsion, dan rincian penelitian yang dilakukan adalah seperti yang terlihat pada Tabel 1.

Pada setiap tahap kegiatan penelitian menggunakan 4 wadah kultur sebagai ulangan. Pemberian pakan dilakukan setiap 6 jam mulai pukul 12.00 (setelah penghitungan), dan pengamatan pertumbuhan populasi rotifera dilakukan setiap hari dan panen pada usia kultur 6 hari.

Penghitungan sampel rotifer dari masingmasing tangki kultur menggunakan, sedgewich rafter counting chamber, ditambahkan 2-3 tetes alkohol 40\%, dan diamati di bawah microskop untuk dihitung kepadatannya. Analisis dilakukan pada nilai kepadatan populasi dan total produksinya per wadah kultur, dan diolah dengan perangkat lunak Microsoft excel untuk menampilkan dalam bentuk grafis.

\section{HASIL DAN BAHASAN}

Hasil uji coba pemeliharaan dengan tangki volume kecil cukup barvariasi antar tahapan percobaan yang telah dilakukan, dan rincian hasilnya sebagai berikut.

\section{Tahap I}

Hasil dari percobaan tahap I memperlihatkan simpangan yang cukup besar dari total produksi rotifer dari masing-masing tangki pemeliharaan, produksi tertinggi terjadi pada tangki kultur 3 sebesar 188,13 x $10^{6}$ ind. rotifer, sedang produksi terendah terjadi pada tangki kultur 4 dengan besaran hanya 77,00 $\mathrm{x}$ $10^{6}$ ind. rotifer (Gambar 2). Pada percobaan tahap I ini volume media pada hari terakhir kultur menjadi $175 \mathrm{~L}$ yang berasal dari penambahan $15 \mathrm{~L}$ fitoplankton $\mathrm{N}$. occulata setiap harinya, sehingga perhitungan kepadatan tertinggi adalah 1.075 rotifer $/ \mathrm{mL}$ dan yang terendah mencapai 440 rotifer $/ \mathrm{mL}$.

Hal ini membuktikan bahwa rotifer dapat dibudidayakan dengan kepadatan yang cukup tinggi, seperti yang dicapai oleh Wati \& Imanto (2007) sebesar 1.867 ind./mL maupun Hendry (1993) yang mencapai 3.000 ind./mL.

Pakan yang disediakan terbukti cukup menunjang produksi rotifer, hal ini membuktikan bahwa ragi (yeast) maupun emulsi minyak ikan (Scott emulsion) mampu dimanfaatkan oleh rotifer disamping jasad pakan alami $N$. occulata. Hal tersebut sesuai dengan pendapat Scott (1981) bahwa rotifer (Brachionus) boleh jadi tergolong pemangsa 


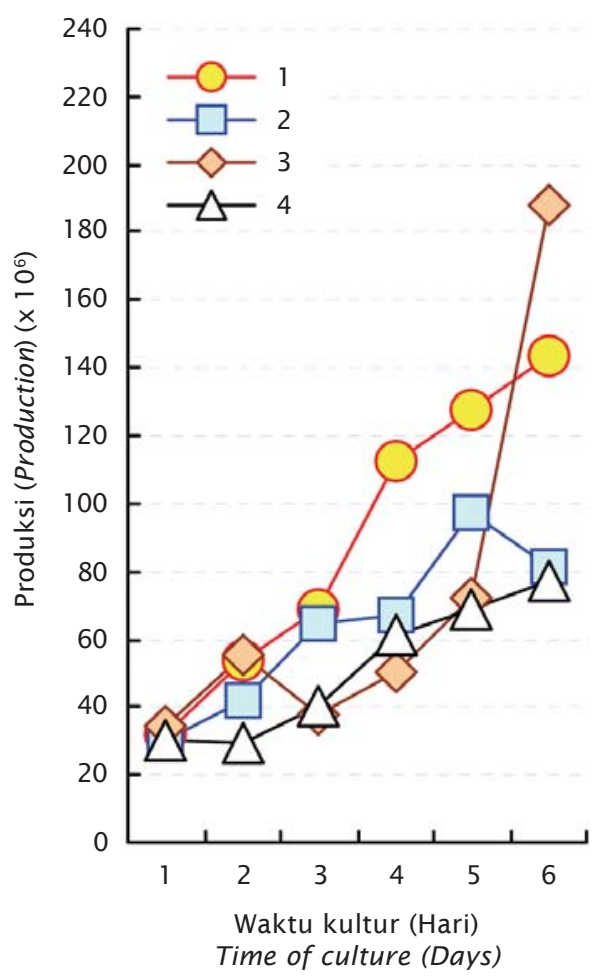

Gambar 2. Jumlah produksi rotifer dari setiap tangki pemeliharaan pada percobaan tahap pertama

Figure 2. Total production of rotifer from each tank at the first trial

campuran, sebagai holozoic di mana partikel makanan dicerna di dalam lambungnya, serta saprozoic pada saat memanfaatkan nutrisi terlarut dari media sekelilingnya

Namun secara keseluruhan tidak terlihat adanya kesamaan pola perkembangan populasi rotifer dari tiap tangki. Pada tangki pertama menunjukkan pertumbuhan yang stabil dibanding tangki yang lain, dan ini cukup memberi gambaran bahwa masih terdapat kelemahan pada manajemen kultur yang belum dapat memberikan hasil yang berulang (replicable).

Volume air yang terbatas diduga mempengaruhi perkembangan populasi rotifer, di mana dengan volume air terbatas sangat rentan terhadap terjadinya perubahanperubahan kualitasnya, Fulks \& Main (1991) dan Rusdi (1997) menyatakan bahwa kualitas air seperti $\mathrm{pH}$, salinitas, dan suhu media besar pengaruhnya pada produksi rotifer.

\section{Tahap II}

Pada pengujian tahap kedua, dilakukan penambahan $40 \mathrm{~L}$ air laut bersih (filtered sea water) disamping meningkatkan pasokan fitoplankton $N$. occulata menjadi $40 \mathrm{~L}$ setiap harinya. Hasil percobaan disajikan pada Gambar 3, dan terlihat ada penurunan total produksi rotifer. Total produksi tertinggi terdapat pada tangki kultur ke-2 dengan $133,50 \times 10^{6}$ ind. rotifer. Terjadinya penurunan performansi produksi pada tahap II diduga karena kerenggangan sediaan pakan terutama ragi akibat penambahan volume media kultur, sehingga kesempatan rotifer menemukan pakannya menjadi semakin rendah, dan ini berakibat pada produktivitasnya. Ragi (yeast) yang disediakan jauh lebih rendah dari dosis yang dikemukakan oleh Orhun et al. (1991) dengan $0,5 \mathrm{~g} / 10^{6}$ ind. rotifer per hari. Meskipun produktivitasnya menurun, tetapi performansi pola perkembangan populasi dari tiap tangki mulai menunjukkan kesamaan, dan besar kemungkinan ini disebabkan oleh peranan fitoplankton $N$. occulata selain sebagai sediaan pakan bagi rotifer juga berfungsi menjaga kualitas media pemeliharaan.

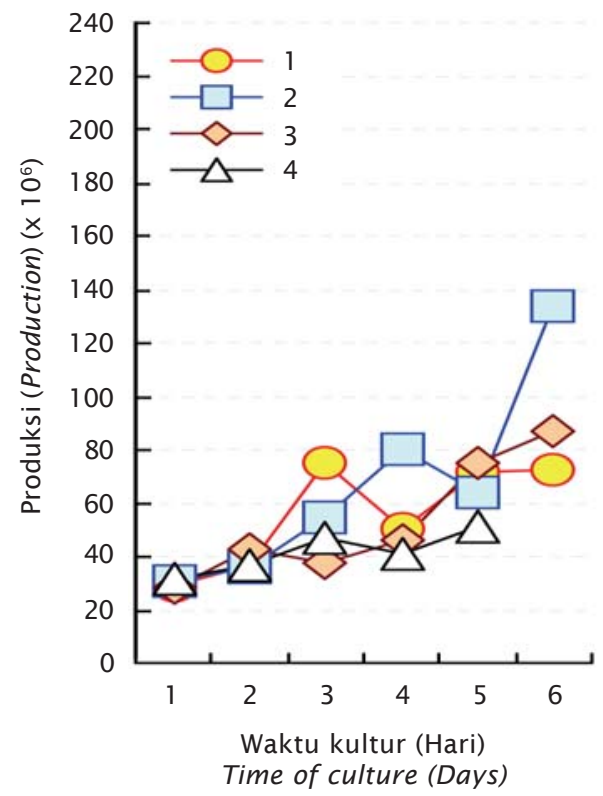

Gambar 3. Jumlah produksi rotifer dari setiap tangki pemeliharaan pada percobaan tahap kedua

Figure 3. Total production of rotifer from each tank at the second trial 


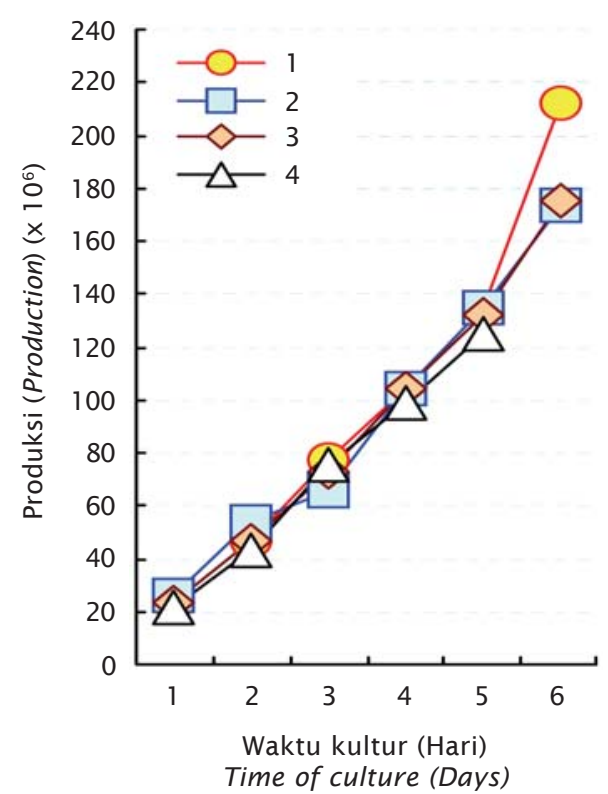

Gambar 4. Jumlah produksi rotifer dari setiap tangki pemeliharaan pada percobaan tahap ketiga

Figure 4. Total production of rotifer from each tank at the third trial

\section{Tahap III}

Pada tahap III, jumlah pemberian ragi ditingkatkan dua kali dari jumlah yang diberikan pada tahap I dan II. Hasil produksi menunjukkan peningkatan yang cukup baik dengan total produksi tertinggi $212,50 \times 10^{6}$ ind. rotifer pada tangki kultur 1 , dan grafik pertumbuhan populasi rotifer relatif sama pada setiap tangki kultur (Gambar 4) dengan simpangan produktivitas dan standard deviasi terkecil dari keempat tangki kultur ada pada tahap III (Tabel 2).
Dari Tabel 2 dan Gambar 5, terlihat dengan jelas penurunan simpangan (SD) dari produktivitas tiap tangki dari masing-masing tahapan percobaan (trial I, II, \& III), dengan kecenderungan yang meningkat. Pada tahap III (trial III) telah dicapai keseragaman produktivitas dengan penyimpangan hanya 12\% (Tabel 2). Ini cukup membuktikan bahwa manajemen kultur pada tahap III sudah cukup baik dengan hasil yang sama/stabil dari tiap ulangan (replicable).

Rata-rata produksi pada tahap III (187 juta rotifer) adalah yang tertinggi dibanding tahap I dan II (122 dan 97 juta), hal ini diduga pada Trial III kondisi kualitas air cukup terjaga dan sediaan pakan (plankton-ragi-scoot emulsion) mencukupi kebutuhan individu rotifer untuk berkembang dan reproduksi. Produktivitas rotifer sangat erat kaitannya dengan kuantitas dan kualitas sediaan pakannya seperti yang dinyatakan Wati \& Imanto (2007) bahwa kombinasi sediaan pakan fitoplankton Nannochloropsis, ragi roti (yeast) dengan penambahan Scott's emultion dan vitamin $B_{12}$ terbukti mampu memberikan pertumbuhan populasi rotifer yang optimal.

Hasil penelitian ini mengindikasikan adanya hubungan antara volume media kultur, padat tebar ideal individu rotifer, dan jumlah sediaan pakan baik yang berupa fitoplankton, ragi roti maupun suplemen pakan dan vitamin.

\section{KESIMPULAN DAN SARAN}

- Volume dan kualitas media kultur sangat menentukan kemampuan reproduksi dan produktivitas dari rotifer.

- Fitoplankton dalam kultur rotifer masih memegang peranan penting sebagai sumber energi utama maupun penetralisir kondisi media kultur, sehingga kualitas kultur fitoplankton harus optimal.

Tabel 2. Persamaan garis regresi dari total produksi rotifer menurut usia kultur dan nilai standard deviasi dari tiap tahap percobaan

Table 2. Regression line of total production of rotifer based on days of culture and standard deviation value from each trial

\begin{tabular}{|c|c|c|c|c|c|}
\hline $\begin{array}{l}\text { Percobaan } \\
\text { Trial }\end{array}$ & $\begin{array}{l}\text { Persamaan garis regresi } \\
\text { Regression line }\end{array}$ & $\mathbf{r}$ & $\begin{array}{l}\text { Produksi rata-rata } \\
\text { Average production } \\
\text { ( } \times 10^{6} \text { ind.) }\end{array}$ & $\left(\times 10^{6}\right.$ & $\begin{array}{l}\text { SD } \\
\text { ind.)/(\%) }\end{array}$ \\
\hline 1 & $y=2.3114 x^{2}+13284 x+29.639$ & 0.9974 & 122.37 & 53.33 & $(44 \%)$ \\
\hline II & $y=18433 x^{2}-11953 x+31388$ & 0.9693 & 97.67 & 3187 & $(33 \%)$ \\
\hline III & $y=2.9312 x^{2}+9.9399 x+8.5504$ & 0.9969 & 187.17 & 2196 & $(12 \%)$ \\
\hline
\end{tabular}




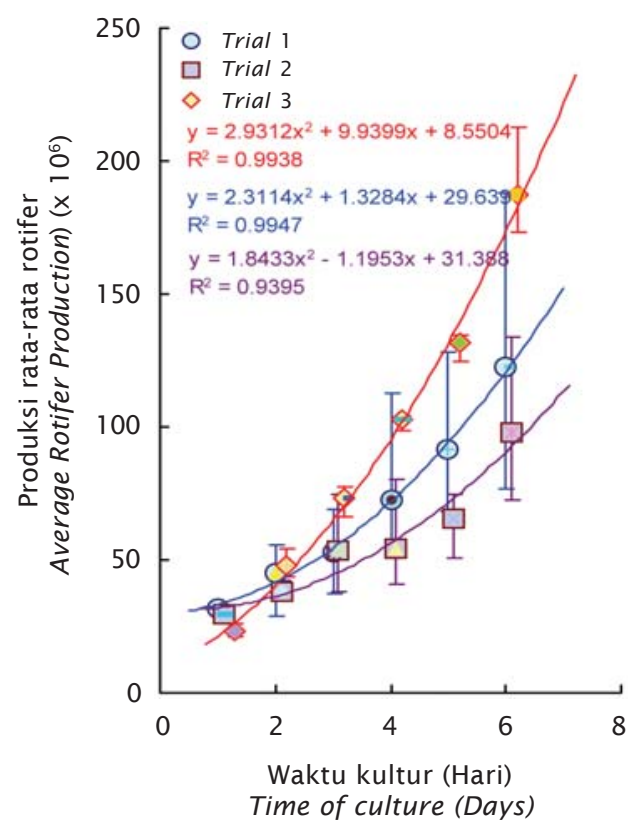

Gambar 5. Pola perkembangan populasi rotifer dari setiap ulangan

Figure 5. Growth pattern of rotifer population from each trial

- Sediaan pakan harus berimbang baik terhadap jumlah individu rotifer maupun kepadatannya berdasarkan volume media kultur rotifer, dan frekuensi pemberian pakannya mengacu pada kecepatan pemanfaatannya oleh rotifer.

- Metode total harvest atau panen total sangat tepat diaplikasikan pada kultur rotifer dengan media terbatas.

- Penelitian lebih lanjut untuk pengelolaan kultur low volume high density diarahkan pada padat tebar optimal, suplemen pakan dalam bentuk suspensi yang lebih stabil (tidak mudah mencemari media) dan kombinasinya dengan tingkat salinitas dan suhu media kultur.

\section{DAFTAR ACUAN}

Christiansen, M.E. \& Yang, W.T. 1976. Feeding Experiment on The Larva of Fiddler Crab Uca pugilatot (Brachyura, Ocypodidae), Reared in the Hatchery. Aquaculture, 8: 91-98.

Fukusho, K. 1989. Biology and Mass Production of the Rotifer, Brachionus plicatilis (1). International Journal of Aquaculture and Fisheries Technology, 1: 68-76.
Fulks, W. \& Main, K.L. 1991. Rotifer and Microalgar Culture Systems. Proceedings of a U.S - Asia Workshop. Honolulu, Hawaii, p. 1-364.

Giliberto, S. \& Mazzola. 1981. Mass culture of Brachionus plicatilis with An Integrated system of tetraselmis suecica and Saccharomyces cerevisiae. The Louisiana State University. J. Word Maricul. Soc., 12(2): 61-62.

Hendry. 1993. Pengaruh Dosis $\alpha$-Tokoferol yang Berbeda Terhadap Pertumbuhan Populasi Brachionus plicatilis. Skripsi Program Studi Budidaya Perairan, Fakultas Perikanan. Institut Pertanian Bogor, 140 hlm.

Ismi, S. \& Wardoyo. 1997. Penggunaan Nannochloropsis oculata Awetan dan yang Diperkaya untuk Kultur Rotifer. J. Pen. Perik. Indonesia, 3(4): 67-72.

Liao, I.C., Su, M.S., \& Su, H.M. 1991. An Overview of Live Feed Production System Design in Taiwan. In Fulks and Main, W.K.L. (Eds.). Rotifer and Mikroalgae System. Proceeding of a U.S.-Asia Workshop. Honolulu-Hawaii, p. 135-150.

Melianawati, R. \& Imanto, P.T. 2004. Pemilihan Pakan Alami Larva Ikan Kakap Merah. Lutjanus sebae. J. Pen. Perik. Indonesia. 10(1): 21-24.

Orhun, R.M., Johnson, S.R., Kent, D.B., \& Ford, R. 1991. Practical Approach to High Density Production of The Rotifer, Brachionus plicatilis. In Fulks and Main, W.K.L.(Eds.). Rotifer and Mikroalgae System. Proceeding of a U.S.-Asia Workshop. Honolulu-Hawaii, p. 73-78.

Rahmasari, M. 1989. Studi Pertumbuhan Rotifer Brachionus plicatilis dengan Pakan Chlorella sp., Tetraselmis, dan Ragi Roti. Skripsi. Fakultas Perikanan, Institut Pertanian Bogor, $72 \mathrm{hlm}$.

Rusdi, I. 1997. Pertumbuhan populasi rotifer (Brachionus rotundiformis) Type-S pada suhu yang berbeda di Laboratorium. J. Pen. Perik. Indonesia. 3(4): 62-66.

Scott, J.M. 1981. The Vitamin Requirement of The Marine Rotifer Brachionus plicatilis. J. Marine Biology Ass. U.K., 61: 983-994.

Sumiarsa, G.S., Makatutu, D., \& Rusdi, I. 1996. Pengaruh Vitamin B- ${ }_{12}$ dan Pengkayaan Fitoplankton Kepadatan Tinggi Terhadap Kepadatan dan Kualitas Rotifer. Brachionus plicatilis. J. Pen. Perik. Indonesia. 2(2): 3036. 
Utyani. 1992. Pengaruh Pemberian Vitamin $B-{ }_{12}$ pada Berbagai Dosis terhadap Populasi Rotifer Brachionus plicatilis yang Diberi Pakan Chlorella sp. pada Salinitas 17 ppt dan 37 ppt. Skripsi. Program Studi Budidaya Perairan, Fakultas Perikanan. Institut Pertanian Bogor, $54 \mathrm{hlm}$.

Waspada, Mayunar, \& Fatoni, T. 1991. Upaya Peningkatan Gizi Rotifer Brachionus plicatilis untuk Menunjang Keberhasilan Pembenihan Kerapu Macan E. Fuscoguttatus. J. Penel. Budidaya Pantai. 7(2): 73-80.

Wati, M. dan Imanto, P.T. 2007. Kultur Rotifer dengan Beberapa Jenis Pakan dan Kombinasinya. Makalah hasil penelitian belum diterbitkan, $9 \mathrm{hlm}$. 